\title{
Postsynaptic nigrostriatal dopamine receptors and their role in movement regulation
}

\author{
Alexei Korchounov $\cdot$ Michael F. Meyer • \\ Michael Krasnianski
}

Received: 11 February 2010/ Accepted: 22 July 2010/Published online: 16 November 2010

(C) The Author(s) 2010. This article is published with open access at Springerlink.com

\begin{abstract}
The article presents the hypothesis that nigrostriatal dopamine may regulate movement by modulation of tone and contraction in skeletal muscles through a concentration-dependent influence on the postsynaptic D1 and D2 receptors on the follow manner: nigrostriatal axons innervate both receptor types within the striatal locus somatotopically responsible for motor control in agonist/ antagonist muscle pair around a given joint. D1 receptors interact with lower and D2 receptors with higher dopamine concentrations. Synaptic dopamine concentration increases immediately before movement starts. We hypothesize that increasing dopamine concentrations stimulate first the D1 receptors and reduce muscle tone in the antagonist muscle and than stimulate D2 receptors and induce contraction in the agonist muscle. The preceded muscle tone reduction in the antagonist muscle eases the efficient contraction of the agonist. Our hypothesis is applicable for an explanation of physiological movement regulation, different forms of movement pathology and therapeutic drug effects. Further, this hypothesis provides a theoretical basis for experimental investigation of dopaminergic motor control and development of new strategies for treatment of movement disorders.
\end{abstract}

Keywords Dopamine - Movement · Parkinson's disease · Dyskinesia - Treatment

\footnotetext{
A. Korchounov $(\bowtie) \cdot$ M. F. Meyer · M. Krasnianski Parkinson Department, Marienhospital Kevelaer, Basilikastr. 55, 47612 Kevelaer, Germany e-mail: korchounov@yahoo.de

M. Krasnianski

Department of Neurology, Martin Luther Universität Halle-Wittenberg, Halle (Saale), Germany
}

\section{Introduction}

Goal-directed movement is a composite behavioral action, and the ascendant nigrostriatal dopaminergic system plays an important role in movement regulation (Obeso et al. 2008). Nigrostriatal dopamine regulates movements by the influence on the postsynaptic dopamine receptors expressed by striatal neurons (Smith and Villalba 2008). The striatal neurons express two types of receptors accepting the nigrostriatal dopaminergic input, D1 and D2 (BertranGonzalez et al. 2008). Genetically transformed mice with knocked-out genes for D1 or D2 receptors and normal species with pharmacologically induced blockade of these receptors reveal severe movement disorders indicating that both types of receptors are important for movement regulation (Sealfon and Olanow 2000). Some authors propose that D1 and D2 receptors may play differential roles in movement regulation, and their stimulation may cause different motor effects (Walters et al. 2000). However, the experimental design for separate assessment of differential motor effects induced by selective D1 or D2 stimulation is currently unsettled. The planning of experimental designs for investigation of differential motor effects associated with either D1 or D2 stimulation requires hypotheses about the specific motor effects separately induced by selective stimulation of either D1 or D2 receptors.

Based on recent data regarding the physiology of postsynaptic nigrostriatal D1 and D2 dopamine receptors, we hypothesize how D1 and D2 receptors participate in movement regulation and suggest specific motor effects related to each type of receptor. This hypothesis provides a theoretical basis for planning experimental designs to investigate movement regulation and to explain several motor phenomena seen clinically. Experiments based on this hypothesis may lead to the discovery of new treatment 
options for Parkinson's disease and other movement disorders.

\section{Nigrostriatal projections and movement regulation}

Nigrostriatal projections play an important role in movement control. These projections consist of axons arising from nigral cells. The microelectrode studies indicate that the same single nigral cell is active during movements around a given joint, both when agonists are predominant and induce flexion movements as well as when antagonist muscle activation predominates to induce extension (Schultz et al. 1983; Crutcher and DeLong 1984). A lesion of nigral neurons leads to simultaneous dysfunction of agonist and antagonist muscles in animal models of parkinsonism (Stern 1966) and idiopathic PD (Hoefer and Putnam 1940). Similarly, punctuate and highly localized striatal lesions also cause a simultaneous dysfunction in agonist and antagonist muscle after stereotactic damage (Hore and Vilis 1980; Kato and Kimura 1992) or striatal neurotoxin administration (Wardas et al. 1999). These data indicate that the single nigrostriatal projection simultaneously influences the pool of striatal neurons responsible for motor activity in both muscles of agonist-antagonist muscle pair.

The terminals of single nigrostriatal axons have a high degree of arborization. The branches of the single nigral projection innervate both striosome and matrix compartments of the striatum (Gerfen et al. 1987). The terminal arborization from a single axon usually covers a striatal volume extending $1.5-2.0 \mathrm{~mm}$ rostrocaudally, $0.7-1.0 \mathrm{~mm}$ dorsoventrally and $1.0-1.5 \mathrm{~mm}$ mediolaterally to supply $1.12 \mathrm{~mm}^{3}$ of striatal volume (Matsuda et al. 2009) that respects approximately 75,000 of striatal neurons (Oorschot 1996). These nigral axons transport dopamine to the striatum. The released nigrostriatal dopamine regulates movements by the action on two types of $\mathrm{G}$ protein-coupled postsynaptic dopamine receptors, D1 and D2 (Bloch et al. 2003). These receptors differ in their chemical structure, interaction with intracellular signal systems, pathways of signal transduction toward other neural structures, characteristics of coding genes, evolutionary origin, and independently acquired mechanisms of dopamine binding (Callier et al. 2003).

The mapping of D1 and D2 receptors reveals a high density of both receptors in the striatum and overlapping of their distribution in both striosome and matrix compartments of striatum (Boyson et al. 1986; Dewar and Reader 1989; Hersch et al. 1995). Thus the single nigral axon may influence both D1 and D2 receptors in the pool of striatal neurons responsible for movement activity of agonistantagonist muscle pair. This integrated dopaminergic control involves two dopamine-dependent effects occur in skeletal muscle during movement: acceleration of contraction in an agonist and tone reduction (reduced resistance to passive stretch) in an antagonist (Takakusaki et al. 2003). Experimentally, the acceleration of agonist contraction increases in response to dopaminomimetics and decreases with dopamine antagonists (Meintzschel and Ziemann 2006). At a clinical level, this parallelism can be seen with nigrostriatal dopamine depletion that leads to parkinsonism, characterized by coexistent brady- or hypokinesia with decreased acceleration of agonist muscle contraction and rigidity or tone increase (Verhave et al. 2009); in contrast, striatal dopamine excess is modeled clinically as coexistent hyperkinesia and muscle hypotonia (Rylander et al. 2009).

The interaction between dopamine and striatal D1- and D2-receptors occurs simultaneously with tone and contraction modulation during movement leading one to consider that D1 and D2 may be distinguished in tone and contraction regulation on the follow manner:

\section{Dopamine-dependent tone and contraction regulation}

D1 and D2 receptors express distinct patterns of affinity to dopamine and interact differently with one another depending on synaptic concentrations of neurotransmitter (Zheng et al. 1999; Gerlach et al. 2003). The nanomolar concentrations of dopamine interact preferentially with D1 receptors (dissociation constant $740 \mathrm{nM}$ (Niznik et al. 1986, p. 8401), whereas micromolar concentrations are needed for prominent D2 receptor activation (dissociation constant $117 \mu \mathrm{M}$ (Gerlach et al. 2003, p. 1123). The nanomolar or micromolar dopamine concentrations are detected in different behavioral motor patterns. The nanomolar dopamine concentrations are detected at rest (Abercrombie et al. 1989). The micromolar concentrations are associated with volitional movement activity (Hattori et al. 1994; Murphy et al. 2001).

Both resting nanomolar and movement-associated micromolar dopamine concentrations are depleted in PD (Hefti et al. 1980; Schwarting and Huston 1996; King and Finlay 1995) and have behavioral correlates. At rest, there is disinhibited muscle tone manifested as muscular rigidity, a phenomenon that is associated with pathologically reduced resting nanomolar concentrations of dopamine acting at D1 nigrostriatal receptors. Thus one can hypothesize that dopamine/D1 interaction regulates muscle tone. During voluntary movements in PD, reduced acceleration of contraction occurs, manifested as bradykinesia, a phenomenon that, according to our hypothesis, is associated with pathologically reduced micromolar dopamine levels acting at D2 nigrostriatal receptors, so that the physiological role of 
D2 receptors may be assumed as a promoting or acceleration of contraction. This assumption is confirmed by the evidence of D2 stimulation during voluntary movement obtained from the PET studies in healthy humans and in PD (Goerendt et al. 2003). The distribution of D1 and D2 receptors within the innervation field of the singular nigrostriatal axon enables simultaneous stimulation of both receptors in the striatal locus somatotopically responsible for motor control in agonist/antagonist muscle pair around the given joint. Thus both D1-mediated muscle tone inhibition and D2-accelerated contraction may be synchronically regulated during movement in the antagonist muscle pair.

Our hypothesis may explain the regulation of movement release in healthy humans.

\section{Implication for normal movement release}

The dopamine concentration rises in the synapse during movement initiation from resting nanomolar to movement-associated micromolar level. The increasing nanomolar dopamine concentration saturates D1 receptors and causes an inhibition of muscle tone in complementary antagonist muscle (down-regulation). The maximal D1 mediated tone reduction occurs as all D1 receptors are saturated. Voluntary movement is associated with nigrostriatal dopamine release and rise of its concentration in the nigrostriatal synapse (Goerendt et al. 2003). During the rise of dopamine concentration the D1 receptors interact with lower dopamine concentrations than D2 so that the D1-mediated tone inhibition must occur before D2-promoted acceleration of contraction. The earlier D1induced tone inhibition decreases the tonic resistance of antagonist muscle and eases the contraction of agonist muscle. The further rising dopamine concentration reaches the level that interact with D2 receptors and accelerates contraction of an agonist muscle (up-regulation). As dopamine concentration is rising further, more D2 receptors became stimulated and acceleration is further facilitated. The contraction is maximally accelerated as all D2 receptors are stimulated. The accelerated contraction causes agonist movement in the given joint. During D2 stimulation by micromolar dopamine concentration the D1 receptors remain stimulated and the muscle tone in antagonist remains inhibited. Quick movements are maximized when tone in antagonist muscles is completely inhibited during maximal acceleration of agonist contraction. Thus, normal movement release is affected due to two dopamine-dependent integrated processes: D2-accelerated contraction in agonist which is facilitated by D1-inhibited tonic resistance in antagonist.
Implications for clinical movement disorders: rigidity and bradykinesia

Our hypothesis of an integrative system that influences D1mediated tone inhibition and D2-accelerated contraction depending on synaptic dopamine concentrations helps to conceptualize pathophysiological mechanisms underlying the clinical symptoms in several dopamine-related movement disorders. Several dopamine-related movement disorders are associated with impaired transmitter/receptor interaction. These disorders are briefly presented from the perspective of the proposed hypothesis.

Reduced dopamine synthesis: idiopathic Parkinson's disease

In this dopamine depleted pathological situation, when resting dopamine levels in the striatal synaptic cleft are below the baseline normal low nanomolar levels, tone cannot be sufficiently inhibited in the D1-dependent system leading to a resting state of hypertonicity and clinical appearance of muscular rigidity. Additionally, as movement starts, the requisite micromolar dopamine levels for normal motor activation are not reached at the D2 system leading to reduced capacity to generate movement (bradykinesia). Without dopaminergic restorative therapy, the progressive loss of dopamine production and release leads to increasingly impaired D1 and D2 stimulation and worsening of rigidity and bradykinesia in the course of disease.

Parkinson-associated motor phenomena: the Froment sign

Our hypothesis explains also the Froment sign: tone augmentation when the contralateral limb moves voluntarily, first reported by Froment in the 1920s and newly reviewed in reference to PD (Broussolle et al. 2007). Voluntary movement induces proprioceptive stimulation that triggers compensatory physiological mechanisms involving postural responses (Kristeva-Feige et al. 1996; Caudron et al. 2008). Similar to the Froment sign in PD, movementinduced proprioceptive stimulation in healthy humans is associated with contralateral tonic EMG burst activity in the resting limb (Baldissera et al. 2008). This EMG activity is thought to be the postural response induced by proprioceptive sensorimotor mechanisms, termed the anticipatory postural adjustment (Massion et al. 1999). This postural response is not clinically detectable in healthy humans but becomes clinically significant as the Froment Sign in PD as a reflection of a hyperactive postural response and the appearance of hypertonicity (rigidity). 
Such postural response hyperactivity is common for dopamine depleted conditions like MPTP-treated monkeys (Filion et al. 1988) or subjects with idiopathic PD (Valkovic et al. 2006). We suggest that the Froment sign develops as a disinhibited anticipatory postural adjustment consequent to the nigrostriatal dopamine deficiency. Our hypothesis helps to explain the Froment sign. Our premise is that dopamine/D1 interaction reduces muscle tone, and the muscular hypertonicity in PD is the consequence of insufficient interaction between pathologically reduced resting nanomolar dopamine level and D1 receptors. With the beginning of voluntary movement involving the contralateral body region, this deficient dopamine/D1 system receives proprioceptive inputs from postural afferents with bilateral influences on the basal ganglia. These afferents induce greater reduction of dopamine/D1 interaction than the resting situation. We suggest that the greater reduction of dopamine/D1 interaction may be caused by further impairment of presynaptic dopamine release by one or more of several neurotransmitters that are activated by proprioreceptive mechanisms with influences on presynaptic nigrostriatal dopaminergic terminals. Putative neurotransmitters include GABA and endogenous endorphins (Ronken et al. 1993; Di Chiara and Imperato 1988; Spanagel et al. 1992) which have both been shown to influence the sensorimotor processing in the striatum and substantia nigra (Bevan et al. 1996; Johnson and Napier 1997; Ramanathan et al. 2002). Thus, the proprioceptive stimulation that occurs with voluntary activation of the contralateral extremity may cause an acute inhibition of presynaptic dopamine release which behaviorally translates into the appearance or enhancement of rigidity in a parkinsonian patient already suffering from dopamine depletion. In the patient without apparent rigidity on the side being tested, this activation procedure can induce rigidity that was not apparent without the activation procedure; in the patient with bilateral rigidity at rest, the activation procedure enhances the rigidity through the same putative mechanism.

\section{Parkinson-associated motor phenomena: freezing}

This proprioceptive involvement may be also hypothetically applicable to parkinsonian freezing or gait blockade. During freezing the patient attempts to step forward but cannot move his legs. In parallel to our explanation of the Froment sign, the attempt to move one leg leads to proprioceptive stimulation of postural responses for the contralateral leg that is used for support and stabilization. This proprioceptive stimulation induces a sudden inhibition of dopamine release on the side of the brain controlling the foot that is being moved forward. Inhibited dopamine release causes diminished D1 stimulation, and as a consequence, muscle tone acutely increases. As dopamine release is acutely impaired, synaptic concentration cannot achieve a level necessary for micromolar D2 activation. Without D2 activation, acceleration of contraction is blocked, movement acceleration cannot occur, and stepping fails.

Our explanation of freezing is supported by the observation that levodopa only poorly improves this symptom: if release is blocked, dopamine cannot act even if it is present inside the presynaptic nigrostriatal terminals. Instead, amantadine is sometimes effective against freezing (Singer et al. 2005), and its effects may be explained by the antiglutamatergic non-dopaminergic action of this drug (Blanchet et al. 1998). Also the extracellularly acting MAO-B-inhibitor rasagiline was shown to have a positive effect against freezing (Coria and Cozar-Santiago Mdel 2008), and according to our hypothesis, this observation would be explained by the enhanced dopamine remaining in the synaptic cleft consequent to this drug's extracellular effects.

Postsynaptic receptor blockade: neuroleptic induced parkinsonism

Neuroleptic treatment may be associated with the occurrence of parkinsonian signs, including rigidity, bradykinesia, tremor, and gait impairment. Radionuclide neuroimaging investigations in subjects with neuroleptic induced parkinsonism document postsynaptic striatal dopamine receptor blockade (Knable et al. 1997) confirming that these drugs interrupt the dopamine/dopaminergic striatal receptor interactions. In this case, however, dopamine production and release remain undisturbed or are even overactive, although dopamine cannot bind on postsynaptic sites because of neuroleptic receptor blockade. Different drugs known to induce neuroleptic-associated parkinsonism share the properties of binding to both D1 and D2 receptors (Reimold et al. 2007). According to the model proposed, failed dopamine/D1 interaction from receptor blockade leads to the disinhibition of muscular tone and the clinical appearance of rigidity, whereas interrupted dopamine/D2 interaction disables the acceleration of muscle contraction, causing slowness of movement or bradykinesia.

Postsynaptic dopaminergic receptor degeneration: atypical parkinsonism (progressive supranuclear palsy, multisystem atrophy of parkinsonian type, cortico-basal degeneration)

Atypical parkinsonism is characterized by degeneration of postsynaptic striatal cells and reduced density of postsynaptic dopamine receptors (Piccini and Whone 2004). The 
reduced density of postsynaptic dopamine receptors leads to insufficient effects of dopamine stimulation. In some of these conditions, nigrostriatal dopaminergic cell loss also occurs, leading to low dopamine levels as well. In the proposed hypothesis, impaired D1 activation lead to tone disinhibition and muscular rigidity, whereas impaired D2 effects induce diminished acceleration of muscle contraction and bradykinesia.

Taken together, all three forms of diminished transmitter/receptor interaction-presynaptic, synaptic and postsynaptic-result in increased tone and impairment of volitionally generated movements.

\section{Implications for clinical hyperkinetic movement disorders: involuntary movements}

The hypothesis of an integrative system that influences D1mediated tone inhibition and D2-accelerated contraction is also applicable for explanation of disorders with excessive involuntary movements.

\section{Levodopa-induced dyskinesia}

Levodopa-induced dyskinesia (LID) occurs in progressive stages of PD when nigrostriatal terminals are decreased in numbers and poorly store dopamine (Del Sorbo and Albanese 2008). Once dopamine is released into the synaptic cleft its interaction with postsynaptic sites escapes normal physiological control mechanisms. Uncontrolled dopaminergic activity with increased synaptic dopamine level overstimulates both the nanomolar responsive D1 receptors and the micromolar responsive D2 receptors. According to our hypothesis, the excessive stimulation of D1 receptors facilitates the tone inhibition leading to muscular hypotonia and reduction of tonic antagonist resistance. The reduced antagonist resistance and additional excessive D2 stimulation can lead to uncontrolled acceleration of contraction in agonist muscle and involuntary movement release. Our model is also in concert with the observation that D1 agonists induce dyskinesia in rodents with lesioned substantia nigra (Taylor et al. 2005) and D1-antagonist may prevent LID. According to our model, D1 antagonists inhibit dopamine/D1 interactions, so that dopamine cannot realize its action on D1 receptors and cannot cause tone reduction. Therefore, muscle tone increases. If dopamine/ D1 interaction is strongly interrupted over prolonged time period, one can consider that muscle tone may increase as an ambient clinical state. The increased tone works against contraction of agonist muscles and may inhibit volitional and non-volitional movements. In this way, the generation of dyskinesia may be prevented. The opposite situation occurs if D1 agonist is given (Delfino et al. 2007), in that
D1 receptors became overstimulated and muscle tone decreases strongly. As muscle tone fails, the acceleration of contraction has no resistance, and even with low levels of ambient D2 stimulation, dyskinetic movement may develop.

Levodopa-responsive dystonia (LRD)

Levodopa-responsive dystonia is a form of treatable dystonia that is highly disabling unless patients receive levodopa. Clinically the disorder appears as a fluctuating condition with early morning signs usually minimal, but progressive slow involuntary movements with continuous tonic muscle tension, painful twisting (dystonia) and pathologic dystonic posture as the day progresses. The acceleration of contraction and voluntary movement release are not affected. LRD is usually responsive to treatment with low dose of levodopa with complete or nearly complete resolution of signs and symptoms. According to our model, the pathologic tone disinhibition may be a consequence of impaired dopamine/D1 interaction. The considered impaired dopamine/D1 interaction is confirmed by treatment efficacy of very low doses of levodopa, because low dosage treatment increases the D1interacting nanomolar dopamine levels and restores the normal tone inhibition.

The voluntary agonist contraction is not affected and higher dosage of levodopa is not necessary for treatment, indicating that dopamine/D2 interaction is not disturbed; otherwise according to our model the disorders of voluntary contraction should be obtained. Drug-induced dyskinesia, typical of Parkinson's disease and higher dosage exposure to levodopa, is not typical for LRD.

Tics

Tics are typically rapid and repetitive involuntary movements. They can occur in any muscle group and often fluctuate in severity and change from body part to body part over time. Tone is not affected in tic disorders, even in the anatomic areas afflicted by tics. The functional neuroimaging revealed an increased postsynaptic D2 receptor density in striatum (Wong et al. 2008) indicating that these receptors may be involved in the pathogenesis of tics. According to our hypothesis, the increased density of postsynaptic striatal D2 receptors may suggest the overactive dopamine/D2 interaction leading to involuntary acceleration of contraction and involuntary movement release. The D1 system remains intact, therefore muscle tone is not altered in the affected muscles. This view is confirmed by the fact that intake of D2 antagonist haloperidol can resolve tics in some patients (Shprecher and Kurlan 2009), whereas the intake of D1 antagonists did not 
Table 1 Changes of nigrostriatal dopamine concentration, dopamine/receptor interaction and clinical motor characteristics in healthy humans and movement pathology

\begin{tabular}{|c|c|c|c|c|c|}
\hline & $\begin{array}{l}\text { Free synaptic } \\
\text { dopamine } \\
\text { concentration }\end{array}$ & $\begin{array}{l}\text { Dopamine/D1 } \\
\text { interaction }\end{array}$ & $\begin{array}{l}\text { Muscle tone } \\
\text { in antagonist }\end{array}$ & $\begin{array}{l}\text { Dopamine/D2 } \\
\text { interaction }\end{array}$ & $\begin{array}{l}\text { Acceleration of muscle } \\
\text { contraction in agonist }\end{array}$ \\
\hline Rest in healthy human & Low & Normal & Normotonic & Not present & Not present \\
\hline Movement in healthy human & Increased & Increased & Reduced & Normal & Normal (physiologic movement) \\
\hline Idiopathic (presynaptic) PD & Reduced & Reduced & Increased (muscular rigidity) & Reduced & Reduced (bradykinesia) \\
\hline Neuroleptic PD & Normal & Reduced & Increased (muscular rigidity) & Reduced & Reduced (bradykinesia) \\
\hline Atypical (postsynaptic) PD & Normal & Reduced & Increased (muscular rigidity) & Reduced & Reduced (bradykinesia) \\
\hline Levodopa-induced dyskinesia & Normal/Increased & Increased & Reduced & Increased & Increased (hyperkinesia) \\
\hline Levodopa-responsive dystonia & Normal & Reduced & Increased & Normal & Normal (physiologic movement) \\
\hline Tics & Normal & Normal & Normotonia & Increased & Tics \\
\hline
\end{tabular}

influence the tic behavior in animal models (McCreary and Handley 1999).

The following table summarizes the changes of nigrostriatal dopamine concentration, dopamine/receptor interaction and clinical motor characteristics in healthy humans and movement pathology (Table 1).

\section{Discussion}

Normal voluntary movement is controlled from different regulation levels. With our model, we hypothesize that dopamine-dependent movement regulation at the nigrostriatal level occurs by modulation of tone and contraction in skeletal muscles through the action of nano- or micromolar dopamine concentrations on the postsynaptic D1 and D2 receptors. We posit that synaptic dopamine concentration sequentially rises during movement from nanomolar D1-interacting to micromolar D2-interacting levels and first inhibits muscle tone through D1 receptors and then accelerates muscle contraction to induce normal movement through D2 receptors. Our model suggests that tone inhibition in antagonist muscles precedes the activation of agonist muscles. The same nigrostriatal axons simultaneously innervate the agonist/antagonist muscle pairs so that the consecutive stimulation of D1 and D2 receptors enables the synchronized D1-mediated tone inhibition and D2-promoted acceleration of contraction in the antagonist muscle pair.

This model is useful for the explanation of normal movement regulation and different forms of movement pathology. Our suggestion of preceding antagonist inhibition before agonist activation during nigrostriatal movement regulation needs experimental confirmation. Although such studies have not yet been performed, cortically based experiments with transcranial magnet stimulation confirm that surround inhibition characterized by antagonist inhibition occurs prior to agonist activation at the cortical level of movement regulation (Shin et al. 2009; Beck et al. 2008; Richardson et al. 2008; Voller et al. 2005, 2006; Sohn and Hallett 2004). Thus, a parallel system at the striatal level is logical, though not yet specifically tested. The key experiments to conduct would involve testing whether rising dopamine concentration first inhibits the muscle tone in antagonist muscle by nanomolar action on D1 receptors and then accelerates contraction in agonist by micromolar action on $\mathrm{D} 2$ receptor. The innervation of both D1 and D2 receptor by the singular nigrostriatal axon within the nigrostriatal locus responsible for movement control in both agonist and antagonist muscle around the given joint makes our hypothesis both plausible and testable and provides a theoretical framework for experimental studies both in a laboratory and clinical arena. Below we highlight suggested experiments to investigate and thereby confirm or refute our hypothesis. The studies on the healthy humans are of particular interest because the changes in central movement regulation during voluntary motor tasks during influence on D1 or D2 receptors may be assessed electrophysiologically, kinematically and dynamically.

\section{Studies in human motor cortex electrophysiology}

The changes of motor cortex excitability assessed by transcranial magnetic stimulation have been obtained after intake of dopaminomimetics (Korchounov et al. 2007) and switching-on deep brain stimulation of subthalamic nucleus (Cunic et al. 2002; Pötter-Nerger et al. 2008). These data indicate that changes in nigrostriatal dopaminergic transmission may be reflected and measured at the level of motor cortex. According to our model, D1 or D2 agonists may improve motor parameters. As reduced surround inhibition was shown to be associated with disturbed movement release and occurrence of dystonia (Beck et al. 2008), in opposite the enhanced surround inhibition may be assumed to improve movement realization. Therefore one may expect that the increased surround inhibition may 
appear after intake of D1 or D2 dopamine agonists. Contrary, the intake of D1 or D2 antagonists may be assumed to decrease the surround inhibition. The technical question is, if the solely intake of D1 ligands will influence only antagonistic part of surround inhibition whereas the solely intake of D2 ligands will exclusively influence the agonist part of surround inhibition. According to our model the diminished surround inhibition may be expected in PD and reverse after switch on deep brain stimulation of subthalamic nucleus. Further our hypothesis predicts the profound fall of motor cortical surround inhibition ipsilateral to the moving hand (facilitation) in PD, providing a basis for the Froment sign. According the previous studies, the short intracortical inhibition may be assumed to be disturbed contralaterally to increasing muscle tone during Froment maneuvre (Voller et al. 2006).

Studies in human functional neurovisualization

Our hypothesis suggests a different role of D1 and D2 receptors in movement regulation. PET techniques enable assessment of both D1 and D2 receptors in vivo in humans (Andrews et al. 1999). According to our hypothesis as movement starts, dopamine first saturates D1 and then D2 receptors. Such sequential saturation should be seen in PET if the investigated subjects perform a motor task associated with nigrostriatal dopamine release. PET studies can be planned in two steps: in the first session the patients perform a motor task after intake of D1 ligand (for example, $\left.\left[{ }^{11} \mathrm{C}\right] \mathrm{SCH} 23390\right)$. It could be expected that immediately before movement starts, the reduction of ligand binding will occur, because releasing dopamine will displace the ligand from the receptor. The time curve of displacement start and maximal displacement should be registered. In the second session the same motor task may be performed after intake of D2 ligand (for example, $\left[{ }^{11} \mathrm{C}\right]$ raclopride). According to our model the already known displacement of $\left[{ }^{11} \mathrm{C}\right]$ raclopride from D2 receptors after movement starts (Goerendt et al. 2003) should occur later than the displacement of D1 ligand.

Additionally our hypothesis suggests that in patients with PD with strong unilateral muscular rigidity the binding of D1 ligands in PET will be asymmetric and increased contralaterally to the more rigid body side.

Performing the electrophysiological investigations and PET studies using the same motor tasks may show the preceding antagonist inhibition in both neurovisualizative and electrophysiological examinations. If so, it may be a strong argument that the inhibition of antagonistic muscular activity during movement is the common principal of central movement regulation at nigrostriatal and cortical regulation levels although exact neurotransmitter mechanisms may differ.
Animal studies

D1 or D2 knock-out mice may serve as reasonable animal models of striatal function, although no model has been developed that selectively knocks out one or the other set of receptors in the striatum without involvement of other dopamine systems in the brain (Sealfon and Olanow 2000). As a first step, however, the currently available knock-out models can be used to investigate our hypotheses and to establish the locomotor effects of selective D1 and D2 ligands.

The mentioned studies are able to be performed in living moving objects because our hypothesis is functionally and clinically oriented. Our model provide the explanation of mechanisms enabling the realization of the goal-directed movement and may sufficiently extend the actual understanding of the role of basal ganglia in regulation of movement sequences and adaptive aspects of movements (Doyon 2008).

Our model is based on recent findings and statements that (Obeso et al. 2008) nigrostriatal somatotopy is organized as the same nigrostriatal projections innervate the antagonist muscle pairs around the same joint (Smith and Villalba 2008); postsynaptic functionally active D1 and D2 dopamine receptors are simultaneously innervated by the singular nigrostriatal axon within the striatal locus somatotopically responsible for motor control in agonist/ antagonist muscle pair around the given joint (BertranGonzalez et al. 2008); D1 receptors interact with nanomolar and D2 with micromolar concentration of dopamine. All these points are not considered by the previous models. In our study, we used data based on direct measurements of dissociation constants for dopamine and its receptors. These assessments reflect exact interactions between dopamine and its binding sites, and such techniques largely replace analytic methods such as microdialysis (Chaurasia et al. 2007).

The previous models of basal ganglia disorders are primarily based on anatomical findings. They differ from ours and have not been able to explain the intimate behavioral interaction between tone and muscle contraction in normal movement or in striatal dopaminergic disorders as Parkinson's disease and various forms of involuntary movements (Wichmann and DeLong 1996). Those models have come under question because of significant discrepancies between the predictions and the observed outcome following lesions of specific nuclei and because of basic questions regarding the anatomic substrate of the models. For example, anatomically the degree of segregation of the basal ganglia-thalamocortical circuits has been questioned (Percheron et al. 1984; Lynd-Balta and Haber 1994; Hedreen and DeLong 1991; Percheron and Filion 1991) and the existence of the proposed indirect pathway through 
the STN has been challenged (Parent and Hazrati 1995a, b). It has also been proposed that GPe may provide another output from the basal ganglia via projections to the reticular nucleus of the thalamus (Hazrati and Parent 1994; Asanuma 1994). The notable and obvious discrepancies of previous models are the failure of thalamic lesion to produce clear akinesia/rigidity (Burchiel 1995) and the lack of predicted disturbances of voluntary movement and the expected abolition of dyskinesias by GPi lesions (DeLong and Georgopoulos 1981; Baron et al. 1996; Dogali et al. 1995; Laitinen 1995; Lozano et al. 1995). In addition, GPe lesions do not appear to reduce drug-induced dyskinesias, as predicted by the model (Blanchet et al. 1994). Some of these discrepancies have been subject of recent articles and reviews (Albin 1995; Chesselet and Delfs 1996). Also these models are not able to provide the explanation of parkinsonian symptoms and drug effects, which are done by our hypothesis.

\section{Limitations of our model}

Although our model provides the explanation for different motor phenomena, it has also limitations. The model is developed in the context that bradykinesia and rigidity are hallmark features of PD. In the statistically based factor analysis of the UPDRS, rigidity and bradykinesia are separate as distinct features, possibly suggesting that their physiological bases may not be linked. According to our hypothesis rigidity appears due to diminished dopamine/D1 interaction whereas bradykinesia is a consequence of reduced dopamine/D2 interaction. On the other hand, no clinical analysis of drug or surgical treatment has ever reported a differential effect on bradykinesia versus rigidity, suggesting that improvements may necessarily have a shared physiological relationship.

The further limitation of our hypothesis is the missed explanation of tremor. This limitation may be due to the fact that we are dealing exclusively with dopaminergic nigrostriatal transmission. The relationship between tremor and dopamine is not clear. First, tremor often shows only poor improvement after levodopa treatment indicating that this symptom of PD is only partially dopamine dependent. Second, three forms of parkinsonian tremor are described and it is not clear, whether each forms underlie the same neurotransmitter disorder (Deuschl et al. 2001). Third, the patients with a tremor-dominant and akinetic-rigid form of PD express different neurochemical and neuropathological changes. So the patients with a tremor-dominant form show predominant degeneration of the medial substantia nigra and the retrorubral field (A8), whereas in akinetic-rigid patients, the lateral substantia nigra was mainly affected (Hirsch et al. 1992; Jellinger 1999). This is also in agreement with a neurochemical study that related region- specific dopamine deficiencies to tremor-dominant as opposed to akinetic-rigid forms (Bernheimer et al. 1973). In humans, positron emission tomography (PET) studies revealed that bradykinesia correlated best with nigrostriatal D2 receptor deficiency (Vingerhoets et al. 1997) whereas tremor-dominant patients showed increased metabolic rates in thalamus and pons (Antonini et al. 1998). Thus, it is not clear to what extent dopamine and tremor are related and whether our model is applicable for explanation of tremor.

Future directions

This hypothesis is offered to prompt clinicians and laboratory scientists to consider striatal dopamine receptor interactions in more detail. The model is not all-inclusive, but it provides a framework for testable experiments in humans and experimental animals. At the molecular biology and neuropharmacological levels, the hypothesis suggests that putative treatments need to consider both D1 and D2 activity for maximal therapeutic efficacy in most movement disorders.

Open Access This article is distributed under the terms of the Creative Commons Attribution Noncommercial License which permits any noncommercial use, distribution, and reproduction in any medium, provided the original author(s) and source are credited.

\section{References}

Abercrombie ED, Keefe KA, DiFrischia DS, Zigmond MJ (1989) Differential effect of stress on in vivo dopamine release in striatum, nucleus accumbens, and medial frontal cortex. J Neurochem 52:1655-1658

Albin LR (1995) The pathophysiology of chorea/ballism and parkinsonism. Parkinsonism Related Dis 1:3-11

Andrews TC, Weeks RA, Turjanski N, Gunn RN, Watkins LH, Sahakian B, Hodges JR, Rosser AE, Wood NW, Brooks DJ (1999) Huntington's disease progression. PET and clinical observations. Brain. 122:2353-2363

Antonini A, Moeller JR, Nakamura T, Spetsieris P, Dhawan V, Eidelberg D (1998) The metabolic anatomy of tremor in Parkinson's disease. Neurology 51:803-810

Asanuma C (1994) GABAergic and pallidal terminals in the thalamic reticular nucleus of squirrel monkeys. Exp Brain Res 101:439-451

Baldissera F, Rota V, Esposti R (2008) Anticipatory postural adjustments in arm muscles associated with movements of the contralateral limb and their possible role in interlimb coordination. Exp Brain Res 185:63-74

Baron MS, Vitek JL, Bakay RA, Green J, Kaneoke Y, Hashimoto T, Turner RS, Woodard JL, Cole SA, McDonald WM, DeLong MR (1996) Treatment of advanced Parkinson's disease by posterior GPi pallidotomy: 1-year results of a pilot study. Ann Neurol 40:355-366

Beck S, Richardson SP, Shamim EA, Dang N, Schubert M, Hallett M (2008) Short intracortical and surround inhibition are selectively reduced during movement initiation in focal hand dystonia. J Neurosci 28:10363-10369 
Bernheimer H, Birkmayer W, Hornykiewicz O, Jellinger K, Seitelberger F (1973) Brain dopamine and the syndromes of Parkinson and Huntington: clinical, morphological and neurochemical correlations. J Neurol Sci 20:415-455

Bertran-Gonzalez J, Bosch C, Maroteaux M, Matamales M, Hervé D, Valjent E, Girault JA (2008) Opposing patterns of signaling activation in dopamine D1 and D2 receptor-expressing striatal neurons in response to cocaine and haloperidol. J Neurosci 28:5671-5685

Bevan MD, Smith AD, Bolam JP (1996) The substantia nigra as a site of synaptic integration of functionally diverse information arising from the ventral pallidum and the globus pallidus in the rat. Neuroscience 75:5-12

Blanchet PJ, Boucher R, Bedard PJ (1994) Excitotoxic lateral pallidotomy does not relieve L-Dopa-induced dyskinesia in MPTP parkinsonian monkeys. Brain Res 650:32-39

Blanchet PJ, Konitsiotis S, Chase TN (1998) Amantadine reduces levodopa-induced dyskinesias in parkinsonian monkeys. Mov Disord 13:798-802

Bloch B, Bernard V, Dumartin B (2003) "In vivo" intraneuronal trafficking of $\mathrm{G}$ protein coupled receptors in the striatum: regulation by dopaminergic and cholinergic environment. Biol Cell 95:477-488

Boyson SJ, McGonigle JP, Molinoff PB (1986) Quantitative autoradiographic localization of the $\mathrm{D}$, and $\mathrm{D}$, subtypes of dopamine receptors in rat brain. J Neurosci 6:3177-3168

Broussolle E, Krack P, Thobois S, Xie-Brustolin J, Pollak P, Goetz CG (2007) Contribution of Jules Froment to the study of parkinsonian rigidity. Mov Disord 22:909-914

Burchiel KJ (1995) Thalamotomy for movement disorders. Neurosurg Clin N Am 6:55-71

Callier S, Snapyan M, Le Crom S, Prou D, Vincent JD, Vernier P (2003) Evolution and cell biology of dopamine receptors in vertebrates. Biol Cell 95:489-502

Caudron S, Boy F, Forestier N, Guerraz M (2008) Influence of expectation on postural disturbance evoked by proprioceptive stimulation. Exp Brain Res 184:53-59

Chaurasia CS, Müller M, Bashaw ED, Benfeldt E, Bolinder J, Bullock R, Bungay PM, DeLange EC, Derendorf H, Elmquist WF, Hammarlund-Udenaes M, Joukhadar C, Kellogg DL Jr, Lunte $\mathrm{CE}$, Nordstrom CH, Rollema H, Sawchuck RJ, Cheung BW, Shah VP, Stahle L, Ungerstedt U, Welty DF, Yeo H (2007) AAPS-FDA Workshop White Paper: microdialysis principles, application and regulatory perspectives. Pharm Res 24:1014-1025

Chesselet MF, Delfs JM (1996) Basal ganglia and movement disorders: an update. Trends Neurosci 19:417-422

Coria F, Cozar-Santiago Mdel P (2008) Rasagiline improves freezing in a patient with primary progressive freezing gait. Mov Disord 23:449-451

Crutcher MD, DeLong MR (1984) Single cell studies of the primate putamen. II. Relations to direction of movement and pattern of muscular activity. Exp Brain Res 53:244-258

Cunic D, Roshan L, Khan FI, Lozano AM, Lang AE, Chen R (2002) Effects of subthalamic nucleus stimulation on motor cortex excitability in Parkinson's disease. Neurology 58:1665-1672

Del Sorbo F, Albanese A (2008) Levodopa-induced dyskinesias and their management. J Neurol 255(Suppl 4):32-41

Delfino M, Kalisch R, Czisch M, Larramendy C, Ricatti J, Taravini IR, Trenkwalder C, Murer MG, Auer DP, Gershanik OS (2007) Mapping the effects of three dopamine agonists with different dyskinetogenic potential and receptor selectivity using pharmacological functional magnetic resonance imaging. Neuropsychopharmacology 32:1911-1921

DeLong MR, Georgopoulos AP (1981) Motor functions of the basal ganglia. In: Brookhart JM, Mountcastle VB, Brooks VB, Geiger
SR (eds) Handbook of physiology. The nervous system. Motor control, sect 1, vol II, pt 2. American Physiological Society, Bethesda, pp 1017-1061

Deuschl G, Raethjen J, Lindemann M, Krack P (2001) The pathophysiology of tremor. Muscle Nerve 24:716-735

Dewar KM, Reader TA (1989) Distribution of dopamine D1 and D2 receptors in rabbit cortical areas, hippocampus, and neostriatum in relation to dopamine contents. Synapse 4:378-386

Di Chiara G, Imperato A (1988) Opposite effects of mu and kappa opiate agonists on dopamine release in the nucleus accumbens and in the dorsal caudate of freely moving rats. J Pharmacol Exp Ther 244:1067-1080

Dogali M, Fazzini E, Kolodny E, Eidelberg D, Sterio D, Devinsky O, Berić A (1995) Stereotactic ventral pallidotomy for Parkinson's disease. Neurology 45:753-761

Doyon J (2008) Motor sequence learning and movement disorders. Curr Opin Neurol 21:478-483

Filion M, Tremblay L, Bedard PJ (1988) Abnormal influences of passive limb movement on the activity of globus pallidus neurons in parkinsonian monkeys. Brain Res 444:165-176

Gerfen CR, Herkenham M, Thibault J (1987) The neostriatal mosaic: II. Patch- and matrix-directed mesostriatal dopaminergic and non-dopaminergic systems. J Neurosci 7:3915-3934

Gerlach M, Double K, Arzberger T, Leblhuber F, Tatschner T, Riederer P (2003) Dopamine receptor agonists in current clinical use: comparative dopamine receptor binding profiles defined in the human striatum. J Neural Transm 110:1119-1127

Goerendt IK, Messa C, Lawrence AD, Grasby MP, Piccini P, Brooks DJ (2003) Dopamine release during sequential finger movements in health and Parkinson's disease: a PET study. Brain 126:312-325

Hattori S, Naoi M, Nishino H (1994) Striatal dopamine turnover during treadmill running in the rat: relation to the speed of running. Brain Res Bull 35:41-49

Hazrati LN, Parent A (1994) Projections from the external pallidum to the reticular thalamic nucleus in the squirrel monkey. Brain 550:142-146

Hedreen JC, DeLong MR (1991) Organization of striatopallidal, striatonigral, and nigrostriatal projections in the macaque. J Comp Neurol 304:569-595

Hefti F, Melamed E, Wurtman RJ (1980) Partial lesions of the dopaminergic nigrostriatal system in rat brain: biochemical characterization. Brain Res 195:123-137

Hersch SM, Ciliax BJ, Gutekunst CA, Flees HD, Heilman CJ, Yung KKL, Bolam JP, Ince E, Yi H, Levey AI (1995) Electron microscopic analysis of $\mathrm{Dl}$ and D2 dopamine receptor proteins in the dorsal striatum and their synaptic relationships with motor corticostriatal afferents. J Neurosci 75:5222-5523

Hirsch EC, Mouatt A, Faucheux B, Bonnet AM, Javoy AF, Graybiel AM, Agid Y (1992) Dopamine, tremor and Parkinson's disease. Lancet 340:125-126

Hoefer P, Putnam T (1940) Action potentials of muscles in rigidity and tremor. Arch Neurol Psychiatry 43:704-725

Hore J, Vilis T (1980) Arm movement performance during reversible basal ganglia lesions in the monkey. Exp Brain Res 39:217-228

Jellinger KA (1999) Post-mortem studies in Parkinson's disease-is it possible to detect brain areas for specific symptoms? J Neural Transm Suppl 56:1-26

Johnson PI, Napier TC (1997) Morphine modulation of GABA- and glutamate-induced changes of ventral pallidal neuronal activity. Neuroscience 77:187-197

Kato M, Kimura M (1992) Effects of reversible blockade of basal ganglia on a voluntary arm movement. J Neurophysiol 68:1516-1534

King D, Finlay JM (1995) Effects of selective dopamine depletion in medial prefrontal cortex on basal and evoked extracellular dopamine in neostriatum. Brain Res 685:117-128 
Knable MB, Heinz A, Raedler T, Weinberger DR (1997) Extrapyramidal side effects with risperidone and haloperidol at comparable D2 receptor occupancy levels. Psychiatry Res 75:91-101

Korchounov A, Ilić TV, Ziemann U (2007) TMS-assisted neurophysiological profiling of the dopamine receptor agonist cabergoline in human motor cortex. J Neural Transm 114:223-229

Kristeva-Feige R, Rossi S, Pizzella V, Lopez L, Erné SN, Edrich J, Rossini PM (1996) A neuromagnetic study of movement-related somatosensory gating in the human brain. Exp Brain Res 107:504-514

Laitinen LV (1995) Pallidotomy for Parkinson's disease. Neurosurg Clin N Am 6:105-112

Lozano AM, Lang AE, Galvez-Jimenez N, Miyasaki J, Duff J, Hutchinson WD, Dostrovsky JO (1995) Effect of GPi pallidotomy on motor function in Parkinson's disease. Lancet 346:1383-1387

Lynd-Balta E, Haber SN (1994) Primate striatonigral projections: a comparison of the sensorimotor-related striatum and the ventral striatum. J Comp Neurol 345:562-578

Massion J, Ioffe M, Schmitz C, Viallet F, Gantcheva R (1999) Acquisition of anticipatory postural adjustments in a bimanual load-lifting task: normal and pathological aspects. Exp Brain Res 128:229-235

Matsuda W, Furuta T, Nakamura KC, Hioki H, Fujiyama F, Arai R, Kaneko T (2009) Single nigrostriatal dopaminergic neurons form widely spread and highly dense axonal arborizations in the neostriatum. J Neurosci 29:444-453

McCreary AC, Handley SL (1999) The thyrotrophin-releasing hormone analogue MK771 induces tic-like behaviours: the effects of dopamine D1 and D2 receptor antagonists. Eur J Pharmacol 369:1-9

Meintzschel F, Ziemann U (2006) Modification of practice-dependent plasticity in human motor cortex by neuromodulators. Cereb Cortex 16(8):1106-1115

Murphy NP, Lam HA, Maidment NT (2001) A comparison of morphine-induced locomotor activity and mesolimbic dopamine release in C57BL6, 129Sv and DBA2 mice. J Neurochem 79:626-635

Niznik HB, Otsuka NY, Dumbrille-Ross A, Grigoriadis D, Tirpak A, Seeman P (1986) Dopamine Dl receptors characterized with r3H]SCH 23390. J Biol Chem 261:8397-8406

Obeso JA, Rodríguez-Oroz MC, Benitez-Temino B, Blesa FJ, Guridi J, Marin C, Rodriguez M (2008) Functional organization of the basal ganglia: therapeutic implications for Parkinson's disease. Mov Disord 23(Suppl 3):548-559

Oorschot DE (1996) Total number of neurons in the neostriatal, pallidal, subthalamic, and substantia nigra nuclei of the rat basal ganglia: a stereological study using the Cavalieri and optical dissector methods. J Comp Neurol 366:580-599

Parent A, Hazrati LN (1995a) Functional anatomy of the basal ganglia. I. The cortico-basal ganglia-thalamo-cortical loop. Brain Res Brain Res Rev 20:91-127

Parent A, Hazrati LN (1995b) Functional anatomy of the basal ganglia. II. The place of subthalamic nucleus and external pallidum in basal ganglia circuitry. Brain Res Brain Res Rev 20:128-154

Percheron G, Filion M (1991) Parallel processing in the basal ganglia: up to a point. Trends Neurosci 14:55-59

Percheron G, Yelnik J, Francois C (1984) The primate striato-pallidonigral system: an integrative system for cortical information. In: Carpenter M, McKenzie JS (eds) The basal ganglia: structure and function. Plenum Press, New York, pp 59-63

Piccini P, Whone A (2004) Functional brain imaging in the differential diagnosis of Parkinson's disease. Lancet Neurol $3: 284-290$
Pötter-Nerger M, Ilic TV, Siebner HR, Deuschl G, Volkmann J (2008) Subthalamic nucleus stimulation restores corticospinal facilitation in Parkinson's disease. Mov Disord 23:2210-2215

Ramanathan S, Hanley JJ, Deniau JM, Bolam JP (2002) Synaptic convergence of motor and somatosensory cortical afferents onto GABAergic interneurons in the rat striatum. $J$ Neurosci 22:8158-8169

Reimold M, Solbach C, Noda S, Schaefer JE, Bartels M, Beneke M, Machulla HJ, Bares R, Glaser T, Wormstall H (2007) Occupancy of dopamine $\mathrm{D}(1), \mathrm{D}(2)$ and serotonin (2A) receptors in schizophrenic patients treated with flupentixol in comparison with risperidone and haloperidol. Psychopharmacology (Berl) 190:241-249

Richardson SP, Bliem B, Lomarev M, Shamim E, Dang N, Hallett M (2008) Changes in short afferent inhibition during phasic movement in focal dystonia. Muscle Nerve 37:358-363

Ronken E, Mulder AH, Schoffelmeer ANM (1993) Interacting presynaptic $\mathrm{K}$-opioid and $\mathrm{GABA}_{\mathrm{A}}$ receptors modulate dopamine release from rat striatal synaptosomes. J Neurochem 61:1634-1639

Rylander D, Recchia A, Mela F, Dekundy A, Danysz W, Cenci MA (2009) Pharmacological modulation of glutamate transmission in a rat model of L-DOPA-induced dyskinesia: effects on motor behavior and striatal nuclear signaling. J Pharmacol Exp Ther 330:227-235

Schultz W, Ruffieux A, Aebischer P (1983) The activity of pars compacta neurons of the monkey substantia nigra in relation to motor activation. Exp Brain Res 51:377-387

Schwarting RK, Huston JP (1996) The unilateral 6-hydroxydopamine lesion model in behavioral brain research. Analysis of functional deficits, recovery and treatments. Prog Neurobiol 50:275-331

Sealfon SC, Olanow CW (2000) Dopamine receptors: from structure to behavior. Trends Neurosci 23(Suppl 10):34-40

Shin HW, Sohn YH, Hallett M (2009) Hemispheric asymmetry of surround inhibition in the human motor system. Clin Neurophysiol 4:816-819

Shprecher D, Kurlan R (2009) The management of tics. Mov Disord 24:15-24

Singer C, Papapetropoulos S, Gonzalez MA, Roberts EL, Lieberman A (2005) Rimantadine in Parkinson's disease patients experiencing peripheral adverse effects from amantadine: report of a case series. Mov Disord 20:873-877

Smith Y, Villalba R (2008) Striatal and extrastriatal dopamine in the basal ganglia: An overview of its anatomical organization in normal and Parkinsonian brains. Mov Disord 23(Suppl 3):534-547

Sohn YH, Hallett M (2004) Disturbed surround inhibition in focal hand dystonia. Ann Neurol 56:595-599

Spanagel R, Herz A, Shippenberg TS (1992) Opposing tonically active endogenous opioid systems modulate the mesolimbic dopaminergic pathways. Proc Natl Acad Sci USA 89:2046-2050

Stern G (1966) The effects of lesions in the substantia nigra. Brain 89:449-478

Takakusaki K, Habaguchi T, Ohtinata-Sugimoto J, Saitoh K, Sakamoto T (2003) Basal ganglia efferents to the brainstem centers controlling postural muscle tone and locomotion: a new concept for understanding motor disorders in basal ganglia dysfunction. Neuroscience 119:293-308

Taylor JL, Bishop C, Walker PD (2005) Dopamine D1 and D2 receptor contributions to L-DOPA-induced dyskinesia in the dopamine-depleted rat. Pharmacol Biochem Behav 81:887-893

Valkovic P, Krafczyk S, Bötzel K (2006) Postural reactions to soleus muscle vibration in PD: scaling deteriorates as disease progresses. Neurosci Lett 401:92-96

Verhave PS, Vanwersch RA, van Helden HP, Smit AB, Philippens IH (2009) Two new test methods to quantify motor deficits in a 
marmoset model for Parkinson's disease. Behav Brain Res 200:214-219

Vingerhoets FJ, Schulzer M, Calne DB, Snow BJ (1997) Which clinical sign of Parkinson's disease best reflects the nigrostriatal lesion? Ann Neurol 41:58-64

Voller B, St Clair Gibson A, Lomarev M, Kanchana S, Dambrosia J, Dang N, Hallett M (2005) Long-latency afferent inhibition during selective finger movement. J Neurophysiol 94:1115-1119

Voller B, St Clair Gibson A, Dambrosia J, Pirio Richardson S, Lomarev M, Dang N, Hallett M (2006) Short-latency afferent inhibition during selective finger movement. Exp Brain Res 169:226-231

Walters JR, Ruskin DN, Allers KA, Bergstrom DA (2000) Pre- and postsynaptic aspects of dopamine-mediated transmission. Trends Neurosci 23(Suppl 10):41-47
Wardas J, Konieczny J, Lorenc-Koci E (1999) The role of striatal adenosine $\mathrm{A}_{2 \mathrm{~A}}$ receptors in regulation of the muscle tone in rats. Neurosci Lett 276:79-82

Wichmann T, DeLong MR (1996) Functional and pathophysiological models of the basal ganglia. Curr Opin Neurobiol 6:751ГÇô758

Wong DF, Brasić JR, Singer HS, Schretlen DJ, Kuwabara H, Zhou Y, Nandi A, Maris MA, Alexander M, Ye W, Rousset O, Kumar A, Szabo Z, Gjedde A, Grace AA (2008) Mechanisms of dopaminergic and serotonergic neurotransmission in Tourette syndrome: clues from an in vivo neurochemistry study with PET. Neuropsychopharmacology 33:1239-1251

Zheng P, Zhang XX, Bunney BS, Shi WX (1999) Opposite modulation of cortical $\mathrm{N}$-methyl-D-aspartate receptor-mediated responses by low and high concentrations of dopamine. Neuroscience 91:527-535 